\title{
Myoepithelioma of the Nasal Cavity
}

\author{
${ }^{1} \mathrm{D}$ Ramesh, ${ }^{2} \mathrm{Grace}$ Corrine Khong, ${ }^{3} \mathrm{~V}$ Sumathi
}

\begin{abstract}
Myoepithelioma is a rare tumor of the salivary glands. Only three cases of myoepithelioma in the nasal cavity have been reported. A 29-year-old male presented to us with epistaxis and nasal obstruction. There was a fleshy mass occupying the right middle meatus. Biopsy showed evidence of myoepithelioma and an endoscopic excision of the tumor was done. Histopathological examination of the resected tumor was consistent with myoepithelioma. Due to its rarity, the nature of the tumor is not known and regular follow-ups are needed for early detection of recurrence and malignancy.
\end{abstract}

Keywords: Endoscopic surgery, Myoepithelioma, Nasal cavity, Salivary gland.

How to cite this article: Ramesh D, Khong GC, Sumathi V. Myoepithelioma of the Nasal Cavity. Clin Rhinol An Int J 2015;8(2):89-91.

\section{Source of support: Nil}

Conflict of interest: None

\section{INTRODUCTION}

Myoepithelioma is a rare tumor of the major and minor salivary glands representing only 1 to $1.5 \%$ of all salivary gland tumors. ${ }^{1}$ It is most commonly found arising from the parotid gland and $40 \%$ of myoepithelioma cases arise from the minor salivary glands. Apart from salivary glands, myoepithelioma has also been reported in breast tissue, lung, soft-tissue and rarely, the bone. ${ }^{2}$

Myoepithelioma from the nasal cavity is rare with only three cases that have been reported so far. ${ }^{3,4}$ It arises from minor salivary glands that are normally found in the nasal cavity at a concentration of 7 to 10 glands per $\mathrm{mm}^{2} .5$

This benign tumor is diagnosed mainly through histopathology examination that will show either a plasmacytoid or a spindle cell appearance. A mixture of both features can also be seen. Immunohistochemistry staining can be done to support the diagnosis. It is also useful in detecting any malignant changes in the lesion.

\footnotetext{
${ }^{1}$ Consultant, ${ }^{2}$ Resident, ${ }^{3}$ Consultant and Head

${ }^{1-3}$ Department of Otorhinolaryngology, Sundaram Medical Foundation, Dr Rangarajan Memorial Hospital, Chennai Tamil Nadu, India

Corresponding Author: D Ramesh, Consultant, Department of Otorhinolaryngology, Sundaram Medical Foundation, Dr Rangarajan Memorial Hospital, Chennai, Tamil Nadu, India e-mail: dr.dramesh@yahoo.com
}

This is a case of a 29-year-old male patient with myoepithelioma arising from the nasal septum that was managed with endoscopic wide local excision of the tumor.

\section{CASE REPORT}

A 29-year-old man presented to us with a history of nasal obstruction and occasional epistaxis for the past 3 months. On examination, there was a pale fleshy mass in the right nasal cavity (Fig. 1). It was neither sensitive to touch nor did it bleed on touch. Probing was possible in all areas except the medial aspect. There was clinically no cervical lymphadenopathy. Contrast-enhanced computed tomographic (CECT) scan of the paranasal sinuses showed a nonenhancing mass occupying the entire right middle meatus with no obvious deformity of the septum and medial wall of the maxilla (Fig. 2). A biopsy was taken in the outpatient department and it was reported as myoepithelioma (Fig. 3).

Under general anesthesia, endoscopic wide local excision of the mass was done. The base of the mass was found to be attached to the nasal septum. This pedicle was cauterized and the mass was removed with moderate bleeding. A clear margin of the base was removed. The rest of the nasal cavity was normal. Histopathological examination was reported as salivary gland tumor suggestive of myoepithelioma. The lesion showed sheets and trabecula of cells enclosing cystic spaces filled with myxoid connective tissue. The cells were of plasmacytoid appearance with eccentrically placed nuclei. The lesion was covered by pseudostratified columnar epithelium and focally by stratified squamous epithelium.

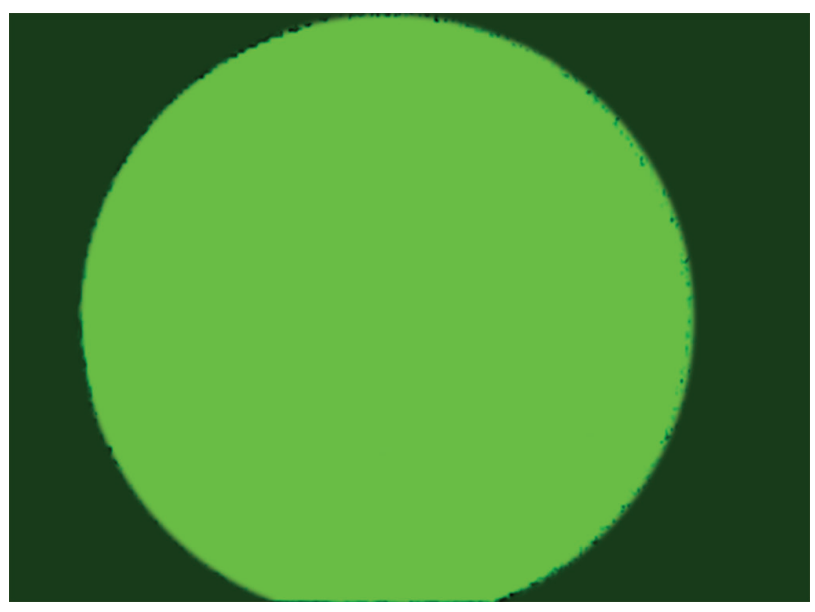

Fig. 1: Endoscopic picture showing a pale fleshy mass in the right nasal cavity 


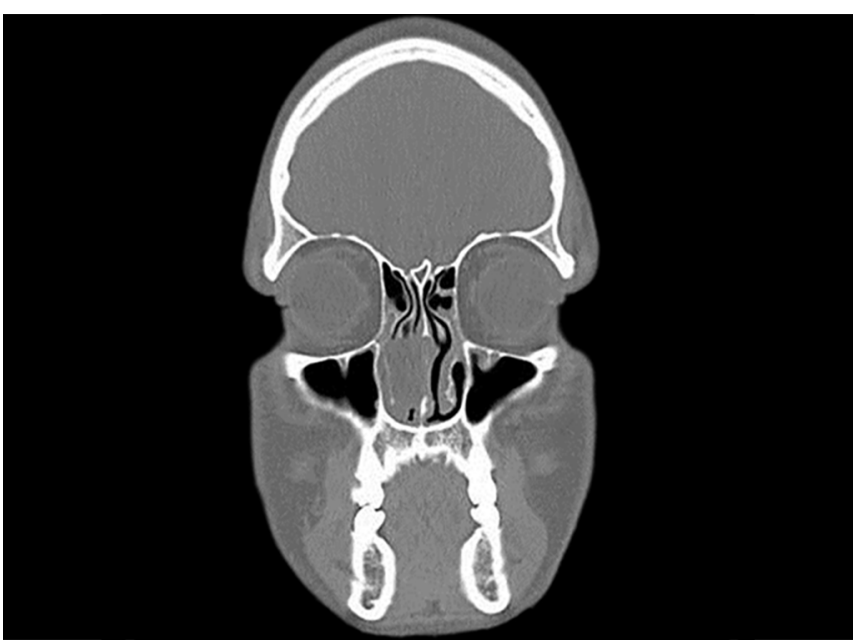

Fig. 2: Contrast-enhanced computed tomographic scan of the paranasal sinuses showing a nonenhancing mass occupying the entire right middle meatus

There was no evidence of recurrence or residual disease after 3 months of follow-up.

\section{DISCUSSION}

This is a case of myoepithelioma arising from the nasal septum. At the clinical presentation, the lack of bleeding on probing and the insensitivity to touch suggested that it was a benign nasal tumor. On CT scan, there was no bony or soft-tissue erosion that further supported its benign presentation.

Biopsy was reported as myoepithelioma and further information on this rare tumor was obtained from literature.

Myoepithelioma is a tumor arising from myoepithelial cells. These type of cells are found mainly in the acini and intercalated ducts of the salivary glands. ${ }^{6,7}$

Minor salivary glands are distributed mainly in the oral cavity. The most common location is the palate. It can also be found in the upper airway and paranasal sinuses. A small concentration of about 7 to 10 glands per $\mathrm{mm}^{2}$ is found in the nasal cavity. The location of minor salivary glands here is postulated to be due to misplaced embryonic epithelial cells or the remnants of the vomeronasal organ. ${ }^{3}$ Hence, myoepithelioma from the nasal cavity is rare with only three cases that have been reported so far. ${ }^{3,4}$

Computed tomography imaging of myoepithelioma may show enhancing and nonenhancing soft-tissue density. The former represents blood vessels amidst epithelial cells and the nonenhancing component shows areas of collagenous or mucoid stroma. ${ }^{5}$

Components of myoepithelial cells can be found in a few other benign salivary gland tumors namely pleomorphic adenoma. ${ }^{8}$ For this reason, myoepitheliomas have also been considered as a variant of pleomorphic adenoma. ${ }^{9}$ Pure myoepitheliomas account only $1 \%$ of all salivary gland tumors. ${ }^{9}$

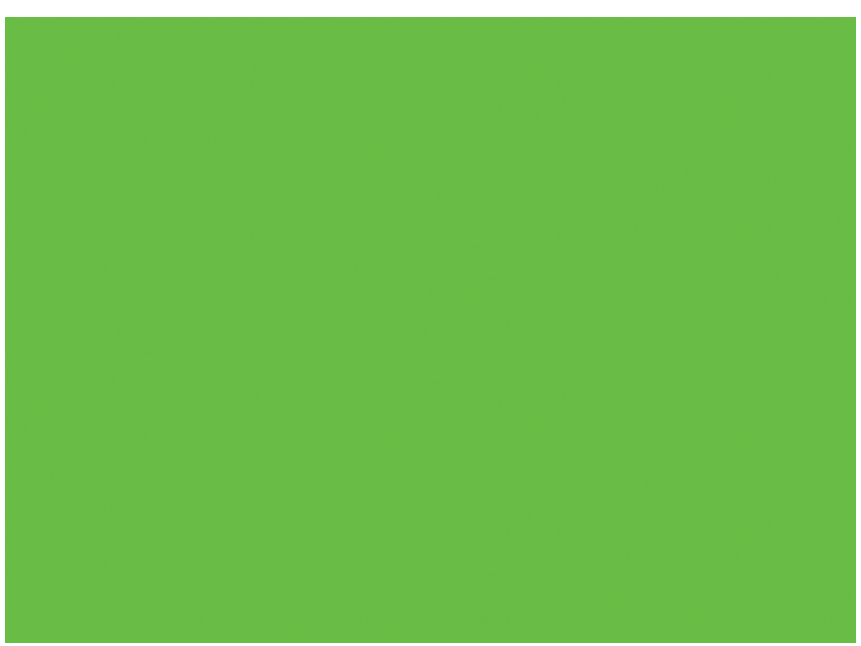

Fig. 3: Histopathological image

Histologically, it is an encapsulated tumor with three distinct histological appearances namely, predominantly spindle cells, plasmacytoid cells or a mixture of both. ${ }^{10}$ The spindle cells variety appears as a storiform swirling pattern or a herringbone, fascicular arrangement. The plasmacytoid variety on the other hand has nests of tumor cells separated by myxoid stroma containing hyaluronic acid. In our case, it was a plasmacytoid appearance with eccentrically placed nuclei.

This tumor stains positive for cytokeratin, smooth muscle actin, vimentin, S100 protein, glial fibrillary acidic protein (GFAP) and epithelial membrane antigen (EMA). The most consistent of all are the cytokeratin, S-100 and smooth muscle actin (SMA). ${ }^{9,11}$

Its malignant counterpart is malignant myoepithelioma. It arises as a malignant transformation of a benign pleomorphic adenoma or rarely benign myoepithelioma. ${ }^{4}$ Ki-67 marker can be used to diagnose malignant myoepithelioma.

Due to its scarcity of reports, there is a lack of information on its progression and outcome. Clinically, its nature is predicted to be similar to pleomorphic adenoma as it is thought to be a part of the same spectrum ${ }^{3}$ with a tendency for malignant transformation. Hence, it is recommended that the same management as that of pleomorphic adenoma should be followed. We proceeded with endoscopic wide local excision of the tumor with clear margins.

As a standard precaution, regular follow-ups are recommended to detect recurrences or subsequent malignant transformation.

\section{ACKNOWLEDGMENT}

All the authors contributed equally in drafting of the article and gave final approval for the publication. 


\section{REFERENCES}

1. Politi M, Toro C, Zerman N, Mariuzzi L, Robiony M. Myoepithelioma of the parotid gland: case report and review of literature. Oral Oncol EXTRA 2005;41:104-108.

2. Park JS, Ryu KN, Han CS, Park YK. Malignant myoepithelioma of the humerus with a satellite lesion: a case report and review of literature. BRJ Radiol 2010;83:e161-e164.

3. Nakaya K, Oshima T, Watanabe M. A case of myoepithelioma of the nasal cavity. Auris Nasus Larynx 2010;37:640-643.

4. Fujikura T, Okubo K. Nasal myoepithelioma removed through endonasal endoscopic surgery: a case report. J Nippon Med Sch 2010;273-276.

5. Som PN, Breinwend-Gensler MN. Anatomy and Pathology, of Salivary Glands. In: PM Som, HD Curtin, editors. Head and Neck Imaging [e-book]. 5th ed. St Louis (US): Mosby; 2011 [cited 2013 Oct 23]. Available at: Inkling.

6. Sayed SI, Kazi RA, Jagade MV, Palav RS, Shinde VV, Pawar $\mathrm{PV}$. A rare myoepithelioma of the sinonasal cavity: case report
[Internet]. Cases Journal 2008 [cited 2013 Nov 11]; 1: 29 [approx 3p.]. Available at: Biomed Central.

7. Wang S, Shi H, Wang L, Yu Q. Myoepithelioma of the parotid gland: CT imaging findings. Am J Neuroradiol 2008;29: 1372-1375.

8. Sperandio FF, Giudice FS, Pinto-Junior DS, SC de Sousa. Myoepithelioma of soft palate: a case report giving special attention to the differential diagnosis [Internet]. J Oral Maxillofac Res 2011 [cited 2014 Jan 1]; 2:1 [approx 5p.]. Available at: PubMed Central.

9. Ferri E, Pavon I, Armato E, Cavaleri S, Capuzzo P, Ianniello F. Myoepithelioma of minor salivary gland of the cheek: a case report. Acta Otolaryngol Ital 2006;26:43-46.

10. Mills SE, editor. Sternbergs's Diagnostic Surgical Pathology. 4th ed. United States: Philadelphia; 2009. p. 943-944.

11. Gore CR, Panicker NK, Chandanwalle SS, Singh BK. Myoepithelioma of minor salivary glands-a diagnostic challenge: report of three cases with varied histomorphology. J Oral Maxillofac Pathol 2013;17:257-260. 